\title{
Performance Evaluation of AODV Routing Protocol using WiMAX on VANET
}

\author{
Sunilkumar M. Bhagat \\ Research scholar, SGB University, Amravati \\ Department of Information Technology \\ MIT Academy of Engineering \\ Pune, India
}

\author{
V.M. Wadhai, Ph.D. \\ Principal \\ Sinhgad Academy of Engineering ( $S A E$ ) \\ ,Pune, India
}

\begin{abstract}
In this paper performance of AODV routing protocol is simulated and evaluated for highway scenario in WiMAX based VANET. In VANET the node mobility is dynamic and changes their topology frequently, have short period to forward the packets between each other. To overcome this problem WiMAX on VANET is configured and simulated to examine performance of routing protocol. This is necessary to reduce Link breakage in order to increase throughput with collaborative efforts of vehicles and fixed station of WiMAX on VANET. The research performance of AODV is examined for highway scenario considering network layer of WiMAX on VANET in terms of Packet delivery Ratio, Throughput, End to End delay, etc.
\end{abstract}

\section{Keywords}

VANET, WiMAX, AODV, Simulator, Topology, link breakage, Packet delivery Ratio, Throughput, End to End delay

\section{INTRODUCTION}

Vehicular Ad hoc Network (VANET) is emerging technologies in the field of inter vehicle communication for the researchers. As per the survey automobile industry has done lot of automation in vehicles. But there is a need of automotive traffic movement on Road. In this context VANETs is becoming interesting area among researchers and automobile industry for improving driving comfort with the help of many safety parameters. [4]

In VANET vehicle can communicate with other vehicle as and when they form network. There are two types of communications vehicle to vehicle i.e. through ad-hoc network and vehicle to road side unit (RSU)

VANET has its own challenges and issues like high mobility of vehicles, dynamic topology, frequent disconnection of network problem, unpredictable behavior of driver and so on. These are issues which attract researchers to reduce the problems. There are many types of routing protocols available for ad hoc VANET. They are classified in proactive, reactive, position based and hybrid which combines these all. [2]

Proactive protocols performance in terms of packet delivery ratio, end to end delay is not up to the mark. Reactive protocols are researchers' first choice however still they have limitations because of ad-hoc nature of VANET. The objective of this paper is therefore to examine performance of AODV protocol in WiMAX on VANET instead of ad-hoc form of VANET.

\section{AODV ROUTING PROTOCOL}

As per the survey, AODV routing protocol is first choice of researchers, so it is selected by means of example for this kind of VANET. AODV provides communication between vehicles with minimal overheads with good packet delivery ratio. But end to end delay is on higher side because of link breakage. Sequence numbers are used for nodes to discover the route in order to avoid loop. Control packets like PREQ, RREP and RERR packets are used to forward data from source node to destination node.

In AODV, communication starts with sources node. It sends RREQ to destination node through neighbor nodes. As RREQ reaches destination node, it replies with RREP to confirm the route. After receiving RREP packet, source nodes start sending actual data. Whenever link breaks; RERR packets are sent to source node. Upon receiving RERR packet, source node starts discovering the route again by sending RREQ packets in VANET [3]

\section{WiMAX}

WiMAX is based on Wireless MAN technology and it is defined as 802.16 as IEEE standard. The IEEE 802.16 Working Group develops standards that address two types of usage models:

- $\quad$ A fixed usage model (IEEE 802.16-2004).

- $\quad$ A portable usage model (IEEE 802.16e).

The mentioned standards support both Time Division Duplexing and Frequency Division Duplexing.

WiMAX operates at higher speed than Wi-Fi covering large distance and it can serve large number of users. WiMAX supports high bandwidth solutions where large spectrum in the excess of $10 \mathrm{MHz}$ is desired considering the existing infrastructure.

The WiMAX physical layer is based on Orthogonal Frequency Division Multiplexing which supports good resistance to multipath. The peak physical layer data rate can be as high as $74 \mathrm{Mbps}$ when operating using a $20 \mathrm{MHz}$ wide spectrum. WiMAX provides two forms of wireless service: Non-Line-of-sight where WiMAX uses a lower frequency range -- $2 \mathrm{GHz}$ to $11 \mathrm{GHz}$ and Line-of-Sight where ranges reaching a possible $66 \mathrm{GHz} .[1][6]$

\section{PERFORMANCE EVALUATION}

We simulate and examine the performance of AODV in WiMAX on VANET with following parameter as shown in Table 1. Then we analyze the performance of AODV routing protocol in terms of data delivery ratio, throughput, end to end delay 
Table 1.Simulation parameter

\begin{tabular}{|l|l|l|}
\hline $\begin{array}{l}\text { Sr. } \\
\text { No. }\end{array}$ & Parameter & Specification \\
\hline 01 & Simulator & QualNet \\
\hline 02 & Simulation Area & $1500 \mathrm{~m}$ X 1500m \\
\hline 03 & Density & Low \\
\hline 04 & Routing Protocols & AODV \\
\hline 05 & Physical Radio & 802.16 \\
\hline 06 & Mac Protocol & 802.16 And $802.16 \mathrm{e}$ \\
\hline 07 & Channel Type & Wireless \\
\hline 08 & Traffic Type & CBR \\
\hline 09 & Source-Destination & Fixed \\
\hline 10 & Velocity & Variable \\
\hline
\end{tabular}

\subsection{QualNet for Simulation Environment}

The highway scenario with four lanes was simulated using QualNet Simulator. For the researcher it is cost effective method to study the wireless network for developing and implementation of VANET routing protocol. This simulation tools helps to evaluate the behavior of VANET with respective to traffic load. Important aspect of such simulator is to create virtual VANET with respective to velocity of vehicles; scalability means number of vehicles on road etc. [7].

Main part of QualNet is analysis functionality. This allows to evaluate the real time performance of routing protocol in virtual environment like $802.11 \mathrm{p}, 802.16,802.16 \mathrm{e}$ in terms of packer delivery ratio, latency time, throughput, end to end delay, Jitter, path loss, total hop count, energy consumtion in different mode and battery capacity in transmit mode.

\subsection{Simulation and Implementation}

For this work WiMAX infrastructure was used for designing and deployment of VANET as shown in Fig 1. The scenario was designed with the help QualNet simulator. There are four fixed base stations( fixed Nodes 1 to 4 ) are installed with WiMAX along the highway with four lanes either side of it and 12 vehicles were running on highway as a mobile stations is enabled with mobile WiMAX features (Nodes 5 to 16). The highway scenario was configured with four wireless channels (Table 2). As mentioned in Table 1; we have set variable velocity to the vehicles and simulation time was 900 s. and we have kept source and destination fixed to examine the performance of AODV routing protocol total 12 vehicles were used to send packets from source to destination and vice versa. Source sends packet of 512 byte size with the interval of $2 \mathrm{sec}$. Start time to send packet over network is set to 100 sec to gain mobility. Packet delivery ratio, throughput end to end delay, jitter was used to examine the performance of the AODV routing protocol at application layer, whereas Data packet loss at network layer and energy consumtion at physical layer. [5]
Table 2. WiMAX on VANET architecture details

\begin{tabular}{|l|l|l|}
\hline $\begin{array}{l}\text { Network } \\
\text { Address }\end{array}$ & Type & Member Node \\
\hline 190.0.0.0 & Wireless Subnet & $\{1,5$ thru 5,13 $\}$ \\
\hline 190.0.1.0 & Wireless Subnet & $\{2,10$ Thru 12 $\}$ \\
\hline 190.0 .2 .0 & Wireless Subnet & $\{3,10,14,15\}$ \\
\hline 190.0.3.0 & Wireless Subnet & $\{4,8$ Thru 10,16 $\}$ \\
\hline 190.0 .4 .0 & Link & $\{1,2\}$ \\
\hline 190.0 .5 .0 & Link & $\{2,3\}$ \\
\hline 190.0 .6 .0 & Link & $\{3,4\}$ \\
\hline
\end{tabular}

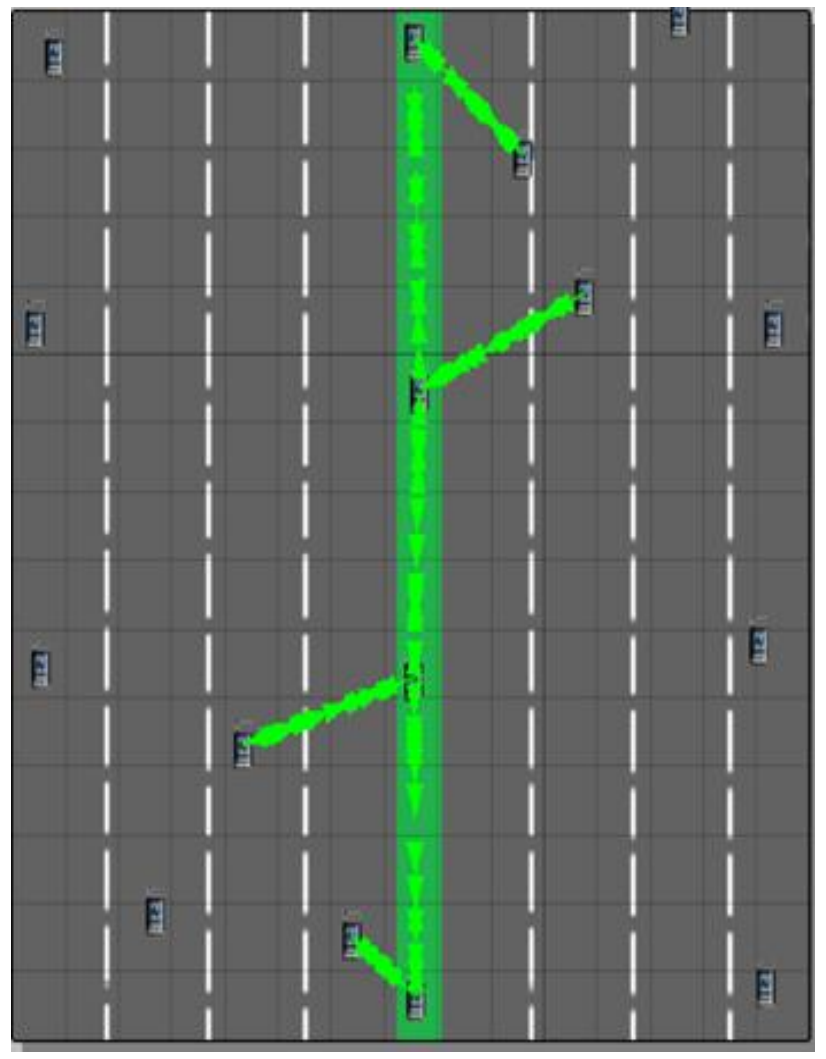

Fig 1: WiMAX on VANET for Highway scenario

\section{RESULTS}

As mentioned in Table 1 Simulation runs for variable velocity of vehicles in WiMAX on VANET for a period of $900 \mathrm{~s}$. Following set of graph shows the Data packet sent by source node and Data packet received at base station 1 and 4 in network layer. According to analysis it is found that total number of data packet lost is 362 packets form fig 2 and fig 3 with following calculation

The total data packet sent by sources is 1600 and received at Node 1 and node 4 is 1238 . Thus total data packet loss is $1600-1238=362$ packets during transmission 


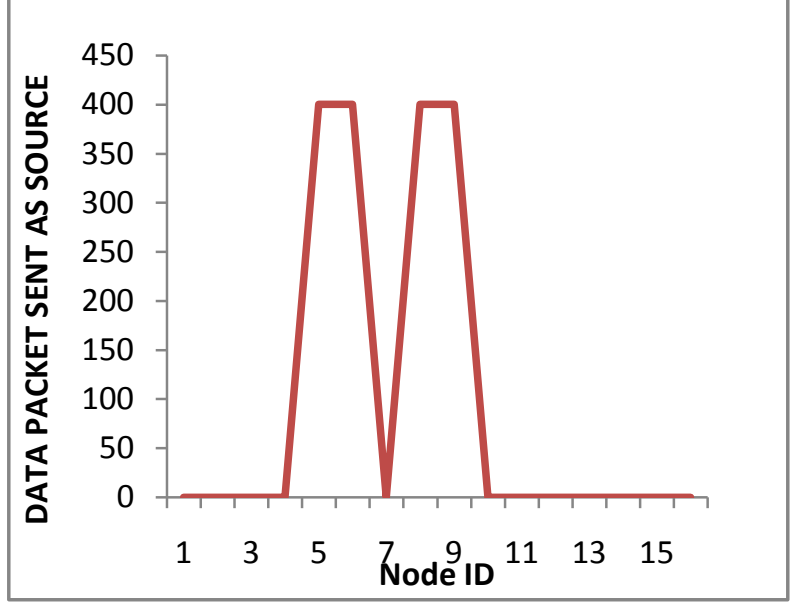

Fig 2 : Data packet sent by source node

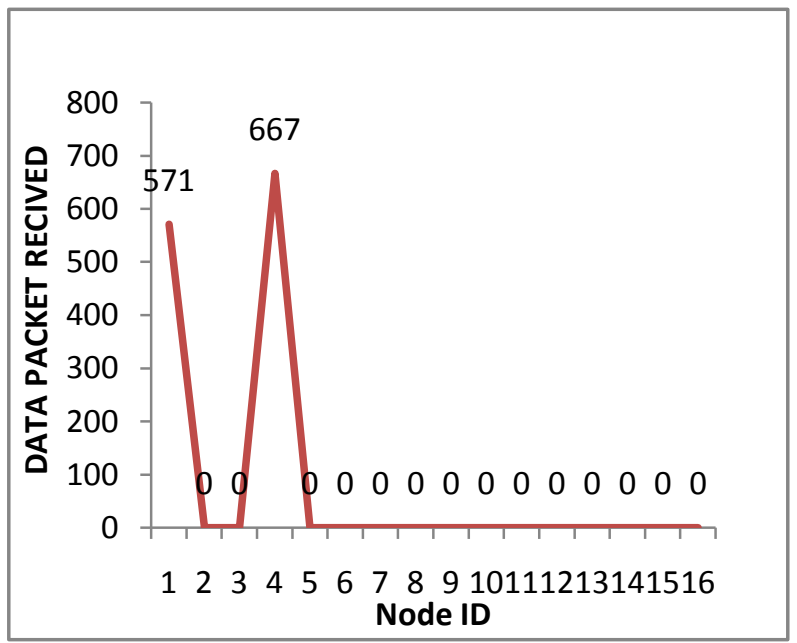

Fig 3: Data packet Received

The next set of graph shows evaluating parameter at application layer like the packet delivery ratio, throughput and end to end delay at base station 1 and node 4 for traffic between vehicles and base station according to CBR application implemented in the scenario. According the analysis as given in the fig 4, fig 5, fig 6 and fig 7 states the performance of AODV in terms of the packet delivery ratio which is satisfactory. Also throughput, end to end delay and Jitter are found satisfactory.

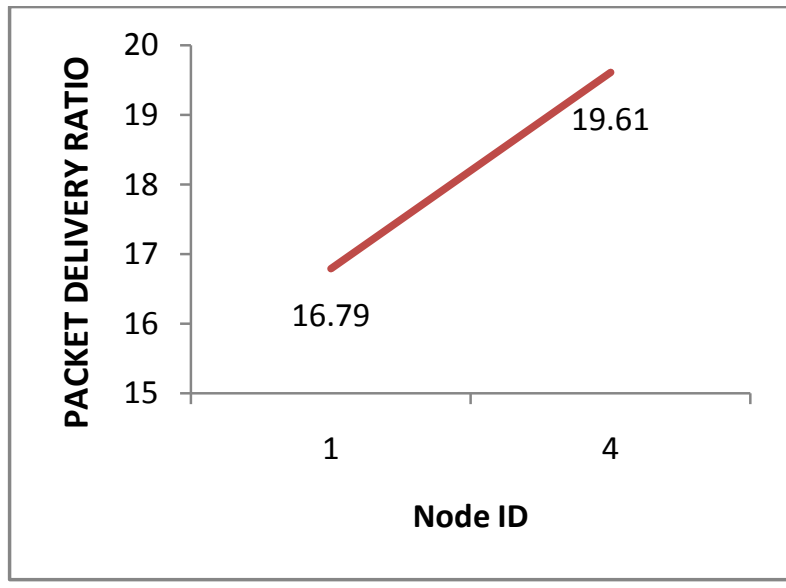

Fig 4: Packet Delivery Ratio

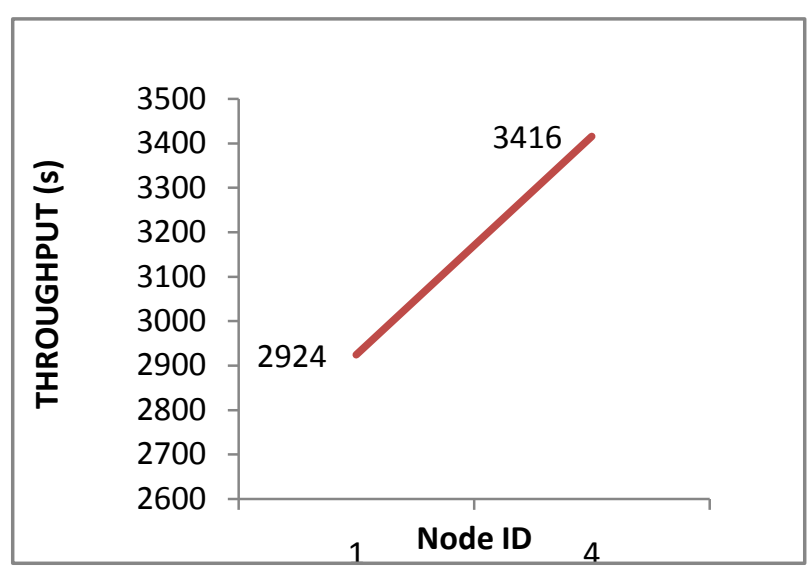

Fig 5: Throughput(s)

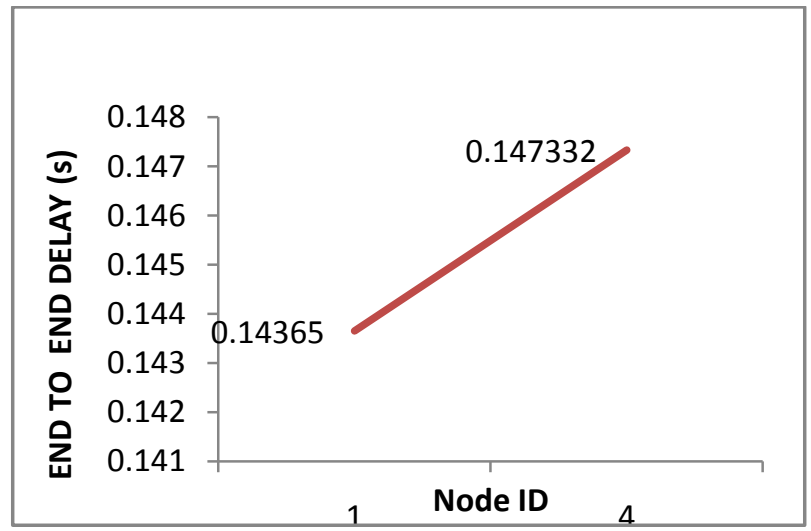

Fig 6: End to End delay

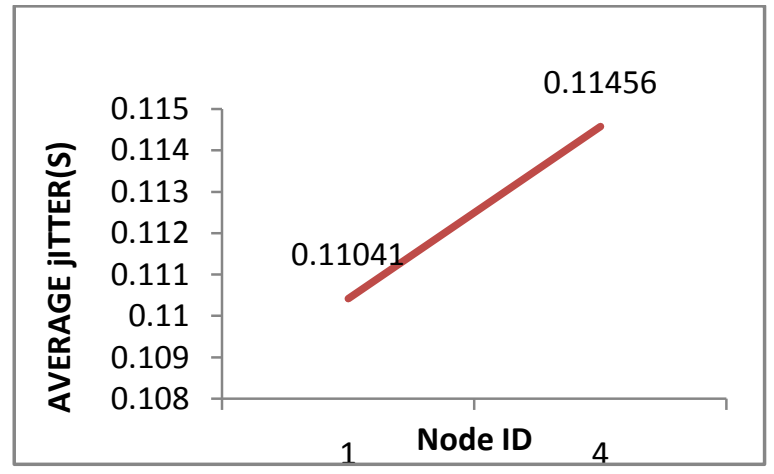

Fig 7: Jitter

The next set of graph shows the result of energy consumption in transmit mode. According to the analysis; the energy consumed by node 5 is more as compared to node 8 because node 5 was involved more in forwarding of packets over network.

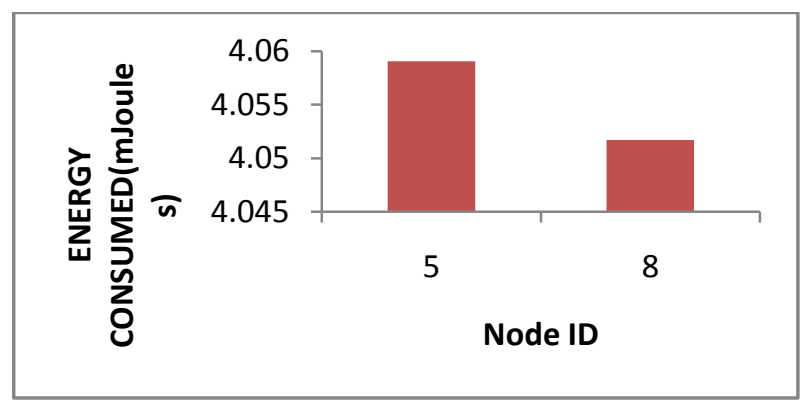

Fig 8: Energy Consumed 
The last set of graph shows number of times link breaks at nodes which implies the number of times the path is discovered. The statistics informs that the path is broken 9 times and on 9 occasions AODV has discovered route.

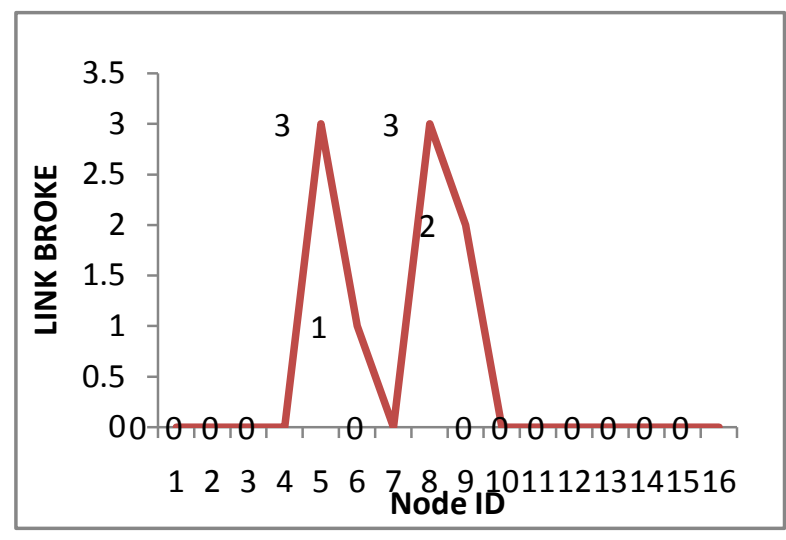

Fig 9: Link Broke

\section{CONCLUSION}

At the end of this work we conclude that we have simulated and implement AODV routing protocol in WiMAX on VANET for highway scenario and it is found that the performance of AODV is satisfactory in terms of Link breakage, Packet delivery ratio, throughput and end to end delay in WiMAX on VANET. Data packet loss is less. The future work of this is to examine the performance of AODV with high density and variable bit rate over WiMAX on VANET

\section{ACKNOWLEDGEMENT}

We take this opportunity to thank Dr. V. M. Thakare, Head Research Center, Amravati University for their valuable guidance and providing all the necessary facilities

\section{REFERENCES}

[1] Muhmad Rizwan Arshad, Shahid Mehmood, salaman Afar "An Evaluation of study of WiMAX and WiFi on Vehicular Ad-Hoc Networks (VANETs)", International Journal of scientific Engineering and Research Volume 3 Issue 12 , December -2012

[2] Takano, A.,Niigata Univ., Niigata,Okada, H. ; Mase, K." Performance Comparison of a Position-Based Routing Protocol for VANET" .IEEE Internatonal Conference on Mobile Adhoc and Sensor Systems, 2007. MASS 2007

[3] Kabiwa, M.S. , Djouani, K. ; Kurien, A. "Performance comparison of IBETX routing metric over AODV and DSDV routing protocols "Wireless Communications and Mobile Computing Conference (IWCMC), 2014 International

[4] Chen, T. Mehani, O. ; Boreli, R.” Trusted routing for VANET" 9th International Conference on Intelligent Transport Systems Telecommunications,(ITST),2009

[5] Prof. Bhagat Sunilkumar Madhusudan, Prof (Dr.) Wadhai V.M" Study Of The Effect Of Velocity On EndToend Delay For V2V Communication In ITS" International Journal of Next-Generation Networks (IJNGN) Vol.4, No.4, December 2012

[6] http://www.tutorialspoint.com/wimax/wimax_salient_fea tures.htm

[7] The QualNet Simulator -http://web.scalablenetworks.com/content/QualNet 